\author{
Alexis PAUL ${ }^{1,2, a}$ \\ Camille BRAUN ${ }^{1, a}$ \\ Amandine MOSNIER ${ }^{1}$ \\ Agnès LAVOIX ${ }^{2}$ \\ Karen SAGORNY ${ }^{2}$ \\ Tiphaine LEFEBVRE ${ }^{3}$ \\ Cyril CHAIGNEAU ${ }^{4}$ \\ Jean-François NICOLAS ${ }^{1,5}$ \\ Marc VOCANSON ${ }^{1,}$ a \\ Audrey NOSBAUM ${ }^{1,5}$, a \\ ${ }^{1}$ CIRI (International Center for Infectiology \\ Research) INSERM U1111, Ecole Normale \\ Supérieure de Lyon, Université Claude \\ Bernard Lyon 1, CNRS UMR5308, 21 \\ avenue Tony Garnier, 69007 Lyon, France \\ ${ }^{2}$ DERMATEC SAS, Espace Lamartine, 9 \\ avenue Victor Hugo, 69160 Tassin la \\ demi-lune, France \\ ${ }^{3}$ Lefebvre Tiphaine, 6 route de Sécheron, \\ 73000 Jacob-Bellecombette, France \\ ${ }^{4}$ SIGVARIS SAS, Z.I. Sud d'Andrézieux \\ Rue Barthélémy Thimonnier, 42170 St-Just \\ St-Rambert Cedex, France \\ ${ }^{5}$ Allergy and Clinical Immunology \\ Department, Lyon Sud University Hospital, \\ 165 chemin Grand Revoyet, 69495 Pierre \\ Bénite cedex, France
}

Reprints: Audrey Nosbaum <audrey.nosbaum@chu-lyon.fr>

(C) The Author(s) 2020

Article accepted on 08/05/2020

\section{Detection of skin alterations in mild-to-moderate chronic venous disease using non-invasive techniques}

\begin{abstract}
Background: Chronic venous disease (CVD) is secondary to venous hypertension, leading to vascular inflammation and tissue changes. The impact of CVD on skin structure and barrier function is not well characterized. Objective: We aimed to assess the characteristics of skin alterations in mild-to-moderate CVD by non-invasive techniques based on a prospective exploratory study. Material \& Methods: Female subjects (30-75 years) with CVD (Stage C2 to C4, CEAP classification) were eligible. Stage C0-C1 CVD subjects were used as controls. Women with leg surgery or a medical history that could impact the results were excluded. The skin changes on lesional (LS) and non-lesional (NLS) areas were assessed by biometric analysis including skin echography, viscoelasticity evaluation, confocal microscopy and trans epidermal water loss (TEWL) measurements. Results: Thirty-four subjects were enrolled. Based on computation of 26 biometric parameters using Principal Component Analysis, a significant difference between LS and NLS zones, regardless of the CEAP class, was evidenced. C2-C4 subjects presented with dermal thickening suggesting oedema associated with decreased cell density, while no difference in skin viscoelasticity was observed compared to the $\mathrm{C} 0-\mathrm{C} 1$ control group. Epidermal structural modifications were associated with increased TEWL correlating with CVD severity. Conclusion: Skin alterations in CVD patients are detectable by non-invasive methods. These findings may help to better assess new therapeutic strategies.
\end{abstract}

Key words: mild-to-moderate chronic venous disease, non-invasive methods, skin barrier function, TEWL

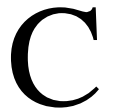

hronic venous disease (CVD) is one of the most frequent diseases worldwide (with a prevalence of 5 to $65 \%$ depending on the population) [1], affecting $40-60 \%$ of females and $15-30 \%$ of males [2, 3]. It is associated with a high socio-economic burden and a significant impact on the quality of life of patients. CVD affects the lower limbs, ultimately leading to chronic venous insufficiency associated with skin changes, in which melanin and haemosiderin deposition participate in the different developmental phases [4]. Based on a meta-analysis of data from patients with mild CVD, in approximately $4 \%$ of patients, the disease worsens each year, representing an implicit problem for countries with an increasingly ageing population [5, 6].

The pathogenesis of CVD is not yet fully understood. Venous reflux is mainly based on venous valve incompetence and venous hypertension, leading to vascular inflammation and tissue changes [7,8]. So far, the impact of CVD vascular inflammation on skin changes has not been well characterized. Although the clinical manifestations of

\footnotetext{
${ }^{a}$ These authors contributed equally.
}

the pathology have been well defined by the Clinical, Etiologic, Anatomic, Pathophysiologic (CEAP) classification (No visible or palpable signs: Stage $\mathrm{C} 0$; telangiectasias, reticular veins: Stage $\mathrm{C} 1$; varicose veins: Stage $\mathrm{C} 2$; leg oedema: Stage C3; hyperpigmentation, eczema, lipodermatosclerosis: Stage C4; skin ulcer: Stages C5-C6) [1], there is little available information on the epidermal and dermal alterations in affected patients.

Histologically, skin abnormalities have been detected at early stages of CVD (Stage C2-C3), such as abnormal collagen deposition and thinning of the epidermis $[9,10]$. Interestingly, the synthesis of type I and III collagen is dysregulated in dermal fibroblasts derived from Stage C2 patients, and this dysregulation is comparable to that observed in smooth muscle cells derived from varicose veins [10]. However, the functional consequences of these findings on skin viscoelasticity and biomechanical properties have not been assessed. CVD patients may also exhibit a compromised epidermal barrier function, assessed by significantly higher transepidermal water loss (TEWL), regardless of the CEAP stage [11]. In addition, a cutaneous down-regulation of some structural genes of the epidermis, including keratin 10 and 14, is detectable in Stage C4 patients [12]. 
Finally, regarding first-line CVD treatment, clinicians currently suggest medical compression therapy, which has a positive effect on the symptoms of the pathology. However, the reported skin dryness and consecutive symptoms, such as itching, lead to reduced comfort and unsatisfactory compliance despite an improved quality of life [13].

To resume, some epidermal and dermal changes may occur during the CVD course suggesting a skin alteration, but a systematic analysis of skin parameters according to CDV severity is lacking.

In this non-invasive study, we aimed to characterize skin changes in the early stages of CVD, before the formation of chronic ulcers, i.e. in Stages C2 to C4. This work describes skin alterations at baseline according to the severity of CVD, using biometric methods.

\section{Material and methods}

This prospective, multicentre, exploratory study was designed to describe skin barrier function in early stages of CVD. Different parameters were studied: a lesional area near the lateral malleolus (lesional skin [LS]) compared to a non-lesional area located $5 \mathrm{~cm}$ under the knee (non-lesional skin [NLS]) (figure 1). All evaluations were performed in the same day.

The study was conducted according to the ethical principles of the latest revision of the Declaration of Helsinki and the guidelines for Good Clinical Practice. The ethics committee (CPP Est III - France) approved the protocol in June 2017. The duration of this study was from October 2017 to July 2018.

\section{Population}

Female subjects aged 30 to 75 years with a skin Phototype I to IV, according to the Fitzpatrick's scale, were eligible. A diagnosis of CVD (Stage C0 to C4 according to CEAP classification [1]) was required, confirmed by a doppler ultrasound examination less than eight months before inclusion (for C2, C3 and C4). Key exclusion criteria were: pregnant or breastfeeding women, surgical interventions of the leg or veins at the area of study, arteriopathy and/or lower limb lymphoedema, leg dermatosis, a medical

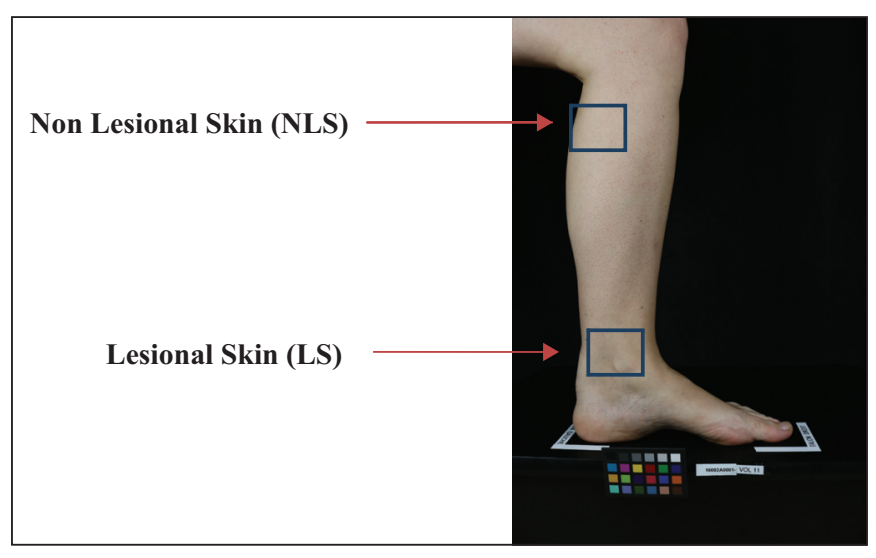

Figure 1. Definition of study zones. history of lower limb thromboembolic diseases or radiation therapy on the area of study. Wearing compression stockings, moisturizer application or waxing/shaving of the legs 48 hours before inclusion were not allowed. Subjects with prolonged sun exposition on study areas within six weeks before inclusion were excluded. Subjects treated by topical and systemic corticosteroids or hormonal therapy within four weeks before inclusion were also excluded. Written informed consent was obtained before any procedure. CEAP class was confirmed at inclusion by a clinical examination.

\section{Quality of life (QoL) based on the CIVIQ-20 questionnaire}

The 20-item questionnaire assesses the impact of the disease on daily life as well as the QoL of patients with CVD. Providing a global index and an outline of four QoL dimensions -"pain" (four items), "physical" (four items), "psychological" (nine items), and "social" (three items)- the questionnaire was initially developed in French (CIVIQ-20) [14]. Items on the CIVIQ-20 scale are scored from 1 to 5. A low score corresponds to greater patient comfort.

\section{Non-invasive biometric evaluation}

The 26 biometric variables based on confocal microscopy, high-resolution ultrasound (HRUS), cutometer skin viscoelasticity and trans epidermal water loss are presented in table 1 .

\section{Confocal microscopy and high-resolution ultrasound (HRUS)}

Imaging was performed using Vivascope $3000^{\mathrm{TM}}$ for in vivo confocal microscopy $[15,16]$ and DUB®SkinScanner75 for the HRUS [17, 18].

Confocal microscopy is a non-invasive technique that enables the identification of cells and tissues (e.g. keratinocytes in the epidermis, papillary dermis, etc.) with nearly histological resolution. Parameters measured were: (i) stratum corneum, stratum granulosum, stratum spinosum and epidermal thickness $(\mu \mathrm{m})$; (ii) cell density (keratinocytes $/ \mathrm{mm}^{3}$ ) in the stratum granulosum, stratum spinosum and epidermis; and (iii) dermal papilla height ( $\mu \mathrm{m})$.

HRUS echography enables skin thickness and dermal density to be measured [10].

In the two designated areas per patient, three series of measurements were performed with both devices in each area, and analyses were performed with the appropriate software; Confoscan $^{\mathrm{TM}}$ and Echoscan ${ }^{\mathrm{TM}}$, respectively.

\section{Skin viscoelasticity}

Skin elasticity was evaluated with a Cutometer®) (MPA 580, Courage and Khazaka GmbH, Germany), an electronic instrument to assess the skin's elastic and biomechanical properties using suction and elongation $[19,20]$. The device generates negative pressure (450 mbar), which causes the test area to be drawn into a probe's aperture. The depth of penetration of the skin into the aperture is determined using a non-contact, optical measuring system. The resis- 
Table 1. The 26 biometric variables studied.

\begin{tabular}{|c|c|}
\hline $\begin{array}{l}\text { Instrument / variables } \\
\text { measured }\end{array}$ & Definition and/or unit \\
\hline $\begin{array}{l}\text { Tewameter }{ }^{\circledR} \\
\text { TEWL }\end{array}$ & Transepidermal water loss $\left(\mathrm{g} / \mathrm{m}^{2} / \mathrm{h}\right)$ \\
\hline Cutometer ${ }^{\circledR}$ & Skin elasticity \\
\hline $\begin{array}{l}\text { R0 - Maximum } \\
\text { deformation of skin }\end{array}$ & $\begin{array}{l}\text { This parameter represents the passive behaviour of the skin in response to force (total viscoelastic } \\
\text { deviation) }\end{array}$ \\
\hline R1 - Firmness & The ability of the skin to return to its original state \\
\hline R2 - Gross elasticity & $\begin{array}{l}\text { Ratio that includes the viscous changes of the skin for both deformation and retraction. Includes } \\
\text { effects of both elasticity of the skin's solid components (elastic fibres, etc.) and viscosity due to the } \\
\text { liquid content of the skin. The higher the value the more elastic the curve }\end{array}$ \\
\hline R3 & $\begin{array}{l}\text { Maximum amplitude of the last suction curve after repeated suction. "Tiring effects" of the skin are } \\
\text { visible, as the amplitude increases with each new suction }\end{array}$ \\
\hline R4 & $\begin{array}{l}\text { Last minimum amplitude compared to the first curve, "tiring effects" of the skin are visible, as the } \\
\text { ability of redeformation decreases with each new suction }\end{array}$ \\
\hline R5 - Net elasticity & $\begin{array}{l}\text { Ratio that excludes viscous changes, focusing the measure on the solid components of the skin. The } \\
\text { higher the value, the more elastic the skin }\end{array}$ \\
\hline R6 & $\begin{array}{l}\text { The portion of viscoelasticity on the elastic part of the curve. The smaller the value, the higher the } \\
\text { distensibility of the elastin fibres }\end{array}$ \\
\hline $\begin{array}{l}\text { R7 - Biological } \\
\text { elasticity }\end{array}$ & Portion of the elasticity compared to the complete curve; the higher the value, the more elastic the skin \\
\hline R8 - Tonicity & Skin recovery; the closer the value to $\mathrm{R} 0$, the greater the ability of the skin to return to its original state \\
\hline R9 - Skin tiredness & $\begin{array}{l}\text { Tiring effects of the skin after repeated suction and release of the skin. The smaller the R9, the smaller } \\
\text { the tiring effects (strain) }\end{array}$ \\
\hline $\begin{array}{l}\text { F0 - Elasticity } \\
\text { F1 - Elasticity }\end{array}$ & $\begin{array}{l}\text { These areas are deducted from the total area of the curve. A completely elastic material will show no } \\
\text { area at all; the closer the value to } 0 \text {, the more elastic the material }\end{array}$ \\
\hline Confocal microscopy & Skin thickness and cell density \\
\hline Epidermal thickness & $\mu \mathrm{m}$ \\
\hline $\begin{array}{l}\text { Stratum corneum } \\
\text { thickness }\end{array}$ & $\mu \mathrm{m}$ \\
\hline $\begin{array}{l}\text { Stratum granulosum } \\
\text { thickness }\end{array}$ & $\mu \mathrm{m}$ \\
\hline $\begin{array}{l}\text { Stratum spinosum } \\
\text { thickness }\end{array}$ & $\mu \mathrm{m}$ \\
\hline $\begin{array}{l}\text { Stratum granulosum cell } \\
\text { density }\end{array}$ & keratinocytes $/ \mathrm{mm}^{3}$ \\
\hline $\begin{array}{l}\text { Stratum spinosum cell } \\
\text { density }\end{array}$ & keratinocytes $/ \mathrm{mm}^{3}$ \\
\hline Epidermal cell density & keratinocytes $/ \mathrm{mm}^{3}$ \\
\hline Dermal papilla height & $\mu \mathrm{m}$ \\
\hline $\begin{array}{l}\text { Epidermal pigmentation } \\
\text { cell density }\end{array}$ & Cells $/ \mathrm{mm}^{3}$ \\
\hline Echography & Skin thickness and dermal density \\
\hline Dermal thickness & $\mu \mathrm{m}$ \\
\hline Total dermal density & $\mathrm{au}$ \\
\hline Deep dermal density & au \\
\hline $\begin{array}{l}\text { Superficial dermal } \\
\text { density }\end{array}$ & $\mathrm{au}$ \\
\hline
\end{tabular}

au: arbitrary unit.

tance of the skin to the negative pressure (firmness) and its ability to return to its original position (elasticity) are displayed as curves (penetration depth in $\mathrm{mm} /$ time) in real time during the measurement. From these curves, a variety of interesting measurement parameters related to elastic and viscoelastic properties of skin surface can be calculated: Rand F- parameters. Definitions are provided in table 1.
Measurements were repeated three times (suction time: 2 seconds; relaxation time: 2 seconds). Results were expressed as the mean of three measurement cycles. One series of measurements was performed for each device and in each area. 
Measurement of TEWL

The TEWL was measured using a Tewameter® (TM300, Courage and Khazaka GmbH, Germany) by applying the measuring probe directly onto the skin in the two designated areas of subjects [21,22]. The measurements, expressed as $\mathrm{g} / \mathrm{m}^{2} / \mathrm{h}$, were taken at room temperature (between 22 and $26^{\circ} \mathrm{C}$ ) with a humidity range from 20 to $40 \%$.

\section{Statistical analysis}

One-way ANOVA followed by a post-hoc test of Tuckey were performed for the TEWL, Cutometer analysis, confocal microscopy and echography parameters in order to compare CEAP classes. The Kruskal-Wallis test followed by the post-hoc Nemenyi test were used as an alternative when the conditions of ANOVA were not met. Pearson correlation between LS to NLS TEWL ratio and age was assessed. A reduced-centred principal component analysis (PCA) was performed on the 26 biometric variables issued from the Tewameter ${ }^{\circledR}$, Cutometer ${ }^{\circledR}$, echography and microscopy. Subjects were then grouped by CEAP classes and/or zones, in order to highlight potential differences in biometric signatures.

The results were analysed with $\mathrm{R}$ software for Windows (Version 3.5.2.). Statistical significance was defined as $\mathrm{p}$ $<0.05$.

\section{Results}

In this nine-month-long study, we enrolled 34 female subjects aged between 37 to 72 years (mean: $56.1 \pm 9.8$ years) suffering from mild-to-moderate CVD. According to CEAP classification, 10 patients were categorized as $\mathrm{C} 0-\mathrm{C} 1$ (control group), 10 as $\mathrm{C} 2$ (symptomatic varicose veins), eight as C3 (oedema without skin lesions) and six as C4 (severe cases of skin lesions excluding ulcers). The mean age of the patients was similar in the four CVD subsets. The main co-morbidities were thyroid disorders, anxiety/depression and arterial hypertension, predominantly in Stage C4. The quality of life questionnaire was completed by the 34 subjects. No main differences in answers to the QoL items was observed between the CVD subsets, apart from four of the 20 items: one in the "physical" dimension, one in the "social" dimension and two in the "psychological" dimension with significantly higher scores in the $\mathrm{C} 4$ class compared to other classes, demonstrating a more altered quality of life in this class (table 2).

There was no failure in screening, and no subject withdrew consent.

\section{Non-invasive parameters discriminate between LS and NLS and categorize CEAP classes of mild-to-moderate CVD in LS}

In this study, we used four non-invasive techniques (Tewameter ${ }^{\circledR}$, Cutometer ${ }^{\circledR}$, US HR echography and confocal microscopy) to characterize the LS and NLS of CVD. First, we analysed the results using principal component analysis (PCA) of the 26 biometric variables issued from the Cutometer® and echography data from the LS and NLS of the 34 patients (figure 2). PCA is an unsupervised clustering method, which groups similar entities together. Figure $2 \mathrm{~A}$ shows the direction and weight of the 12 main biometric variables that form the structure of the two axes of the PCA. The $\mathrm{x}$ horizontal axis was mainly structured by viscoelasticity parameters measured by Cutometer®, i.e. R0 to R9 factors (see table 1 for details), while the y vertical axis grouped parameters associated with dermal density measured by echography. In figure $2 B-D$, each dot represents a non-invasive value (pooled biomechanical and ultrasound measurements) in the LS and NLS for a given patient. There are 68 dots in each panel corresponding to the LS and NLS value in the 34 patients.

Analysis of the PCA results showed:

(i) A clear discrimination between LS and NLS, since the data obtained from the two skin sites were clearly separated on the $\mathrm{x}$ (but not on the $\mathrm{y}$ ) axis (figure 2C). NLS was mostly associated with the R0, R2, R3, R5, R7 and R8 values while $\mathrm{LS}$ was related to R1, R4 and R6 values (figure $2 A, C$ ). These data confirm that the physical and biomechanical properties of LS are altered at all stages of CVD

(ii) A mild discrimination between the CEAP classes for LS but not NLS samples (figure 2D) since the C1, C2 and C3 classes were spread out along the y axis, structured mainly by parameters related to dermal density (superficial, total and deep dermal density). This suggests that dermal density inversely correlated with increased CVD severity.

(iii) No discrimination between the four CEAP classes (figure $2 B$ ) when LS and NLS values were pooled.

Parameters measured using each technique also provided important information which is presented below.

\section{Alteration of dermal structure and biomechanical properties in mild-to-moderate CVD}

Next, we analysed the structure of the dermis by measuring the dermal thickness and density by HRUS (figure $3 A$ ). While no difference of dermal thickness was seen between the different CVD stages in NLS $(p=0.395)$, a significant difference was found in LS $(p=0.019)$ (figure $3 B$ ). Indeed, an increased dermal thickness was observed in the LS of C3 (mean: 1,338 $\pm 132 \mu \mathrm{m}$ ) and C4 stages (mean $1,317 \pm 128 \mu \mathrm{m})$, compared to the $\mathrm{C} 0-\mathrm{C} 1$ control group (mean: $1,085 \pm 228 \mu \mathrm{m})(p=0.023$ and 0.069 , respectively). Concerning dermal density, we observed a slight, but not significant, decrease in density of the whole dermis, represented as a decrease in the LS/NLS ratio, in the C3 (mean: $0.91 \pm 0.24$ ) and $C 4$ (mean: $0.99 \pm 0.35$ ) stages, compared to the control group (mean: $1.27 \pm 0.41$ ) (figure $3 C$ ). Similar data were obtained when the superficial and deep dermis were analysed separately, with a decreased density in the $\mathrm{C} 3$ and $\mathrm{C} 4$ stages compared to control group, but without statistically significant difference (figure $3 D, E$ ).

Finally, we analysed the skin viscoelasticity properties using the Cutometer ${ }^{\circledR}$ which provides nine biomechanical values for each skin site (R0-R9). As expected, the level of skin gross elasticity (R2), firmness (R1) and tonicity (R8) was lower in LS than NLS (LS/NLS ratio <1) (figure $3 F$ ), but surprisingly, we did not observe any significant change in the other parameters (data not shown). More intriguingly, the values of the nine parameters (including R1, R2 and R8) 
Table 2. Clinical data and QoL according to CEAP classification.

\begin{tabular}{|c|c|c|c|c|c|}
\hline \multicolumn{6}{|c|}{ CEAP groups } \\
\hline Parameters & C0-C1 & $\mathrm{C} 2$ & C3 & $\mathrm{C4}$ & Total \\
\hline Patient number $n(\%)$ & $10(29 \%)$ & $10(29 \%)$ & $8(24 \%)$ & $6(18 \%)$ & 34 \\
\hline Age mean \pm SD (years) & $57.0 \pm 10.4$ & $55.8 \pm 9.0$ & $53.6 \pm 11.3$ & $58.5 \pm 10.1$ & $56.1 \pm 9.8$ \\
\hline \multicolumn{6}{|l|}{ Co-morbidities $n(\%)$} \\
\hline Thyroid disorders & $1(10.0 \%)$ & $3(30.0 \%)$ & $1(12.5 \%)$ & $5(83.3 \%)$ & $10(29.4 \%)$ \\
\hline Gastritis & 1 & 1 & 0 & 1 & 3 \\
\hline Anxiety/depression & 0 & 1 & 0 & 0 & 1 \\
\hline Arterial hypertension & 0 & 0 & 0 & 2 & 2 \\
\hline Spinal disc herniation & 0 & 0 & 0 & 1 & 1 \\
\hline $\begin{array}{l}\text { QoL by CIVIQ-20 mean score } \\
(S D)\end{array}$ & & & & & $p$ value \\
\hline \multicolumn{6}{|l|}{ Pain } \\
\hline Pain in the leg & $2.6(0.84)$ & $2.5(0.97)$ & $2.00(1.07)$ & $3.00(0.89)$ & 0.28 (ANOVA) \\
\hline Impairment at work & $2.7(0.82)$ & $2.5(0.85)$ & $2.25(1.16)$ & $3.50(1.38)$ & $0.34(\mathrm{KW})$ \\
\hline Sleeping poorly & $2.6(0.70)$ & $2.4(1.26)$ & $1.75(0.89)$ & $2.67(1.21)$ & $0.267(\mathrm{KW})$ \\
\hline $\begin{array}{l}\text { Standing for long periods of } \\
\text { time }\end{array}$ & $3.0(0.67)$ & $2.8(0.92)$ & $2.50(1.51)$ & $3.67(0.52)$ & 0.186 (ANOVA) \\
\hline \multicolumn{6}{|l|}{ Physical } \\
\hline Climbing several floors & $2.0(1.15)$ & $1.9(0.88)$ & $1.75(1.16)$ & $3.17(1.17)$ & $0.124(\mathrm{KW})$ \\
\hline Squatting/kneeling & $2.4(1.35)$ & $2.2(1.03)$ & $1.75(0.89)$ & $3.67(1.03)$ & $0.042(\mathrm{KW})$ \\
\hline Walking at a good pace & $1.8(0.92)$ & $1.9(0.99)$ & $1.50(0.93)$ & $2.83(0.98)$ & $0.106(\mathrm{KW})$ \\
\hline Doing the housework & $2.5(0.97)$ & $2.1(1.10)$ & $2.62(1.30)$ & $3.33(0.82)$ & $0.193(\mathrm{KW})$ \\
\hline \multicolumn{6}{|l|}{ Psychological } \\
\hline Feeling nervous & $1.9(0.74)$ & $1.9(1.10)$ & $1.75(0.71)$ & $2.17(1.33)$ & $0.954(\mathrm{KW})$ \\
\hline $\begin{array}{l}\text { Having the impression of being } \\
\text { a burden }\end{array}$ & $1.5(0.71)$ & $1.5(0.85)$ & $2.25(1.58)$ & $2.67(1.37)$ & $0.232(\mathrm{KW})$ \\
\hline Being embarrassed to show legs & $2.3(1.42)$ & $2.4(1.35)$ & $3.38(1.60)$ & $4.67(0.52)$ & $0.015(\mathrm{KW})$ \\
\hline Becoming irritable easily & $1.7(0.82)$ & $1.9(1.10)$ & $1.62(0.74)$ & $2.67(1.03)$ & $0.232(\mathrm{KW})$ \\
\hline $\begin{array}{l}\text { Having the impression of being } \\
\text { disabled }\end{array}$ & $1.2(0.42)$ & $1.3(0.67)$ & $1.75(1.39)$ & $3.17(1.6)$ & $0.016(\mathrm{KW})$ \\
\hline Having no desire to go out & $1.9(1.10)$ & $1.5(0.85)$ & $1.75(0.71)$ & $2.33(1.51)$ & $0.618(\mathrm{KW})$ \\
\hline Having to take precautions & $2.1(1.10)$ & $1.7(0.95)$ & $2.25(1.75)$ & $3.00(1.26)$ & $0.264(\mathrm{KW})$ \\
\hline Getting tired easily & $2.6(1.26)$ & $2.1(1.29)$ & $2.88(1.64)$ & $3.33(1.03)$ & $0.293(\mathrm{KW})$ \\
\hline Difficulty in getting going & $2.1(1.37)$ & $1.8(0.63)$ & $2.25(1.39)$ & $3.00(0.89)$ & $0.164(\mathrm{KW})$ \\
\hline \multicolumn{6}{|l|}{ Social } \\
\hline Going to parties & $2.5(1.08)$ & $2.1(1.10)$ & $2.25(1.39)$ & $3.17(1.33)$ & $0.428(\mathrm{KW})$ \\
\hline Performing athletic activity & $2.1(1.10)$ & $1.8(0.79)$ & $2.00(1.07)$ & $3.33(1.21)$ & 0.043 (ANOVA) \\
\hline Traveling by car, plane, etc. & $2.4(0.84)$ & $1.8(0.92)$ & $2.38(1.41)$ & $3.00(1.55)$ & 0.263 (ANOVA) \\
\hline
\end{tabular}

SD: standard deviation; QoL: Quality of Life; KW: Kruskal-Wallis.

(figure $3 F$ ) were stable in both LS and NLS throughout the evolution of the disease, i.e. in the different CVD classes.

\section{Decreased epidermal thickness and density in mild-to-moderate CVD}

Confocal microscopy was used to analyse the thickness of the epidermis and of the different epidermal layers (figure 4A). We first measured the thickness of the epidermis and found no significant difference between the different stages of CVD in LS and NLS, except in the LS of $\mathrm{C} 4$ class showing a reduction in epidermal thickness $(57.56 \pm 7.74 \mu \mathrm{m})$ compared to the $\mathrm{C} 0-\mathrm{C} 1$ control group $(70.15 \pm 15.5 \mu \mathrm{m})$ (figure $4 B)$. Next, we analysed the thickness of each epidermal layer and observed: (i) a decrease in the thickness of the stratum spinosum (SS) in LS of Stage C4 $(31.57 \pm 9.78 \mu \mathrm{m})$ compared to the con- trol group $(45.74 \pm 13.02 \mu \mathrm{m})(p=0.074)$ (figure $4 C)$; (ii) an increased thickness of the stratum granulosum (SG) in LS of C2 (14.16 $\pm 4.67 \mu \mathrm{m}), \mathrm{C} 3(13.73 \pm 3.07 \mu \mathrm{m})$ and C4 $(14.29 \pm 3.14 \mu \mathrm{m})$ stages compared to $\mathrm{C} 0-\mathrm{C} 1$ control group $(10.12 \pm 3.58 \mu \mathrm{m})$ (figure $4 D)$; and (iii) no difference in the stratum corneum thickness between the different classes (figure 4E). Of note, it was not possible to analyse the stratum basale, which follows the superficial dermis structure and is non-linear. In summary, the decrease in epidermal thickness observed in Stage C4 of LS could be mainly attributed to the SS. To verify that the modifications of the epidermal thickness were not due to a flattening of the papilla classically seen in severe CVD, the height of the papilla was measured; no significant change was found, irrespective of the CVD group (figure $4 F$ ).

Finally, we measured epidermal cell density in LS and NLS, and the LS/NLS ratio. A significant decrease in cell density 


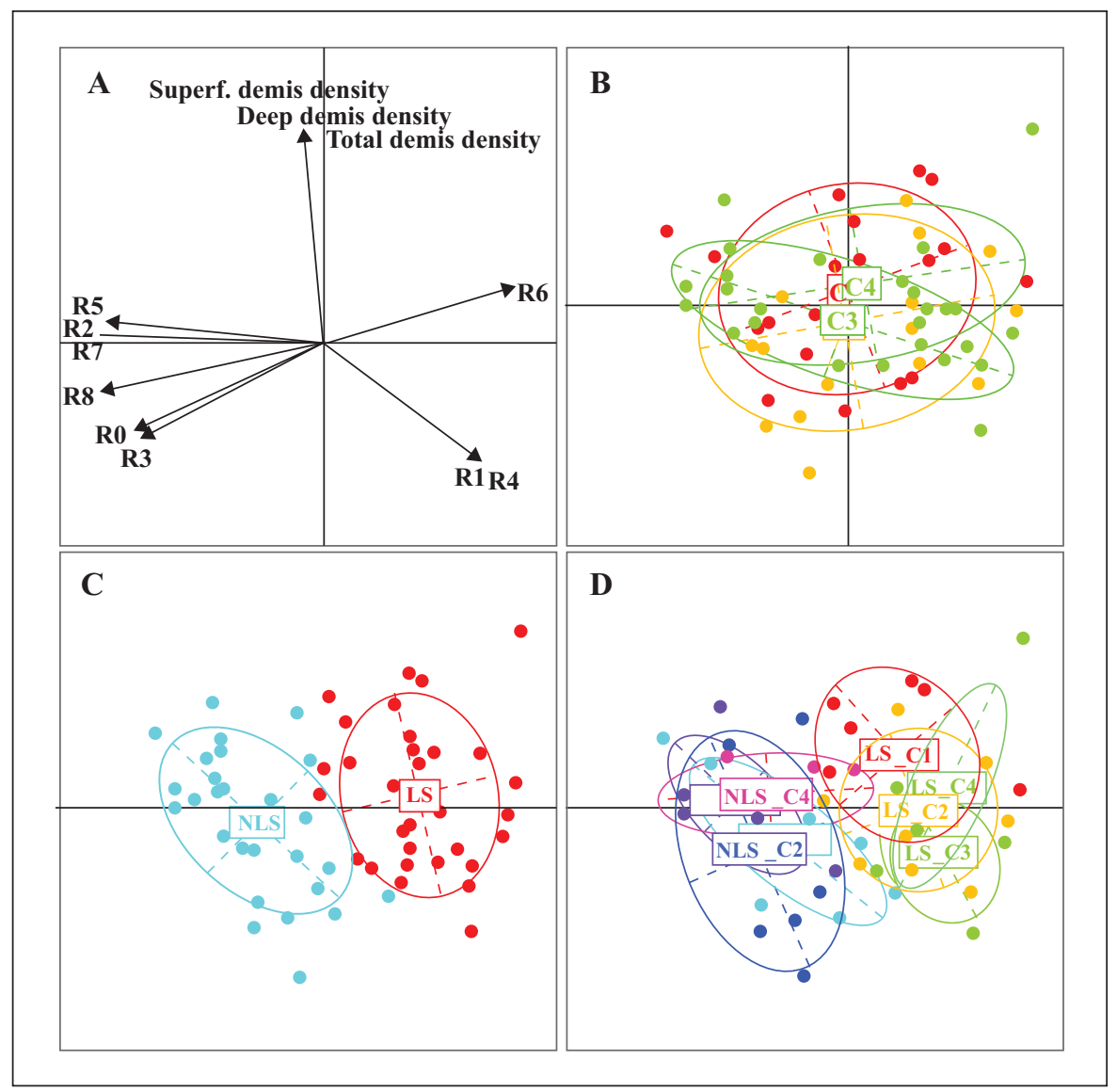

Figure 2. Parameters measured by non-invasive techniques allow to distinguish between LS and NLS using reduced-centred Principal Component Analysis (PCA) $\left(n=34 \times 2\right.$ zones, characterized by 26 biometric variables based on Tewameter ${ }^{\circledR}$, Cutometer ${ }^{\circledR}$, HRUS and confocal microscopy). A) Arrows indicate direction and weighing of vectors representing the 12/26 biometric variables that mainly structure the first two axes of PCA (only variables with absolute contribution superior to 5\% for one of the two axes are represented for clarity). B) Grouping of subjects by CEAP classes. C) Grouping of subjects by zone. D) Grouping of subjects by CEAP class-zone combination.

was observed in Stage C3 and C4 LS epidermis $(4,360 \pm 283$ and $4,327 \pm 484$ keratinocytes $/ \mathrm{mm}^{2}$ ), compared to the control group $\left(4,872 \pm 366\right.$ keratinocytes $\left./ \mathrm{mm}^{2}\right)(p=0.037$ and $p=01043$, respectively) (for LS/NLS ratio, see figure $4 G$ ). Analysis of the epidermal layers confirmed that the cell density reduction mostly concerned the SS. The LS/NLS ratio was statistically different according to the CEAP classes for the epidermal and SS cell density $(p=0.009$ and 0.023 , respectively), unlike for SG (figure 4G-I). Albeit nonsignificant, a trend in cell density reduction was observed in C3 and C4 stages compared to control group in each epidermal layer. Collectively, these results showed that the epidermis is thinner in CVD, due to a predominant cell density reduction of the SS, occurring preferentially in Stages $\mathrm{C} 3$ and $\mathrm{C} 4$.

\section{Functional changes in skin barrier (TEWL) are related to CVD severity}

TEWL measurement, the most validated method to determine a skin barrier alteration, was used to compare LS versus NLS (figure 1) for the different CVD severity stages. In LS, we observed a slight increase in TEWL in Stage C2 (mean: $4.91 \pm 2.12 \mathrm{~g} / \mathrm{h} / \mathrm{m}^{2}$ ), C3 (mean: $4.60 \pm 1.42 \mathrm{~g} / \mathrm{h} / \mathrm{m}^{2}$ ) and $\mathrm{C} 4$ (mean: $5.50 \pm 2.25 \mathrm{~g} / \mathrm{h} / \mathrm{m}^{2}$ ) compared to $\mathrm{C} 0-\mathrm{C} 1$ stages (mean: $3.92 \pm 1.55 \mathrm{~g} / \mathrm{h} / \mathrm{m}^{2}$ ) (figure $5 A$ ). In contrast, no significant TEWL increase was observed in the NLS (figure 5B). Therefore, there was a clear arearelated effect, illustrated by the LS/NLS TEWL ratio that tended to increase from the control to the $\mathrm{C} 4$ group (mean: $0.74 \pm 0.32$ and $1.15 \pm 0.40$, respectively) $(p=0.093)$ (figure 5C). No age-related effect on LS/NLS TEWL ratio was observed (figure 5D). These results suggest a progressive skin barrier defect related to CVD severity, independent of age.

\section{Discussion}

The aim of the study was to non-invasively assess skin modifications occurring in mild-to-moderate CVD. We deciphered the exact changes due to CVD itself, knowing that skin changes are also reported under compressive treatment. We have shown that: i) a CVD-affected skin zone (lateral malleolus) may be differentiated from a control zone (upper part of the leg) based on biometric parameters; and 


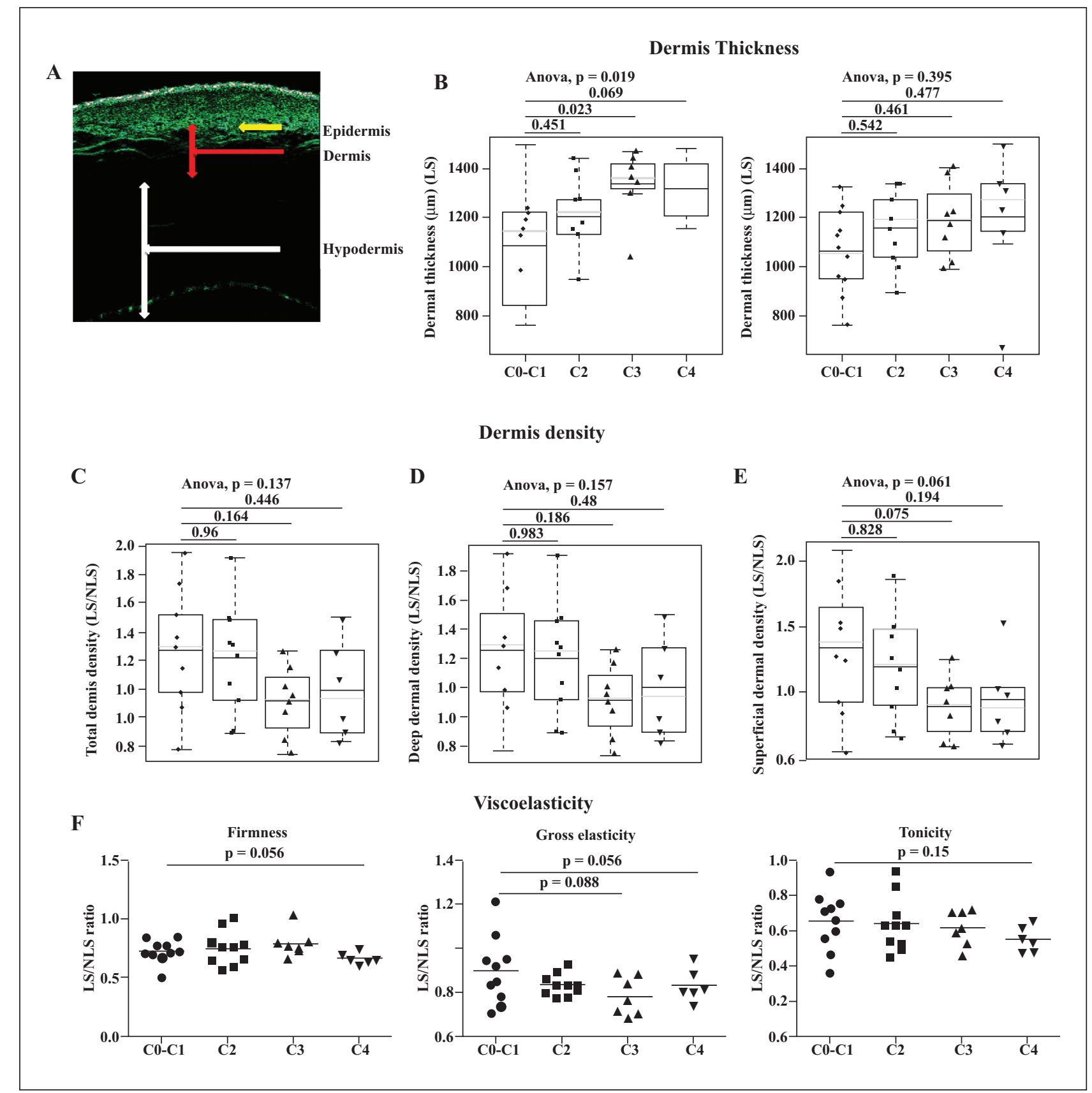

Figure 3. Dermal structure and skin biomechanical properties in mild-to-moderate CVD. A) Illustrative image of echography. Red arrow indicates the dermis, immediately under the epidermis (yellow arrow), and the white arrow indicates the hypodermis (fat layer and connective tissue). B-E) Black symbols represent individual data and horizontal black lines mean values. For each CEAP class, the grey boxplots represent the lower quartile, median (bold line) and upper quartile. Whiskers represent either the maximum value or 1.5 times the interquartile range, whichever is less. Dermal measurements are based on HRUS according to CVD severity. B) Comparison of LS and NLS dermal thickness $(\mu \mathrm{m})$. C-E) Comparison of LS/NLS ratio for total dermal density (C), for deep dermal density (D) and superficial dermal density (E). F) Skin viscoelasticity measurements with Cutometer® (ratio). Comparison of LS/NLS ratio according to CEAP groups for firmness (R1), gross elasticity (R2), and tonicity (R8).

ii) the skin structure is modified in CVD, with a dermal distension and epidermal thinning associated with an increased TEWL. Taken together, and in accordance with the findings of Metcalfe et al. [9], our results suggest the presence of a dermal oedema, induced by fluid influx from venous vessels, and an epidermal barrier defect in the early stages of CVD.
In summary, we have demonstrated that among the noninvasive parameters measured, viscoelasticity and dermis density (superficial, deep, total) are those that provided the most significant contribution to CEAP correlation for $\geq$ Stage $\mathrm{C} 2$. Therefore, the Cutometer ${ }^{\circledR}$ and HRUS parameters may be used to detect skin alterations, and in particular tissue oedema, rather than the CEAP classification, which 


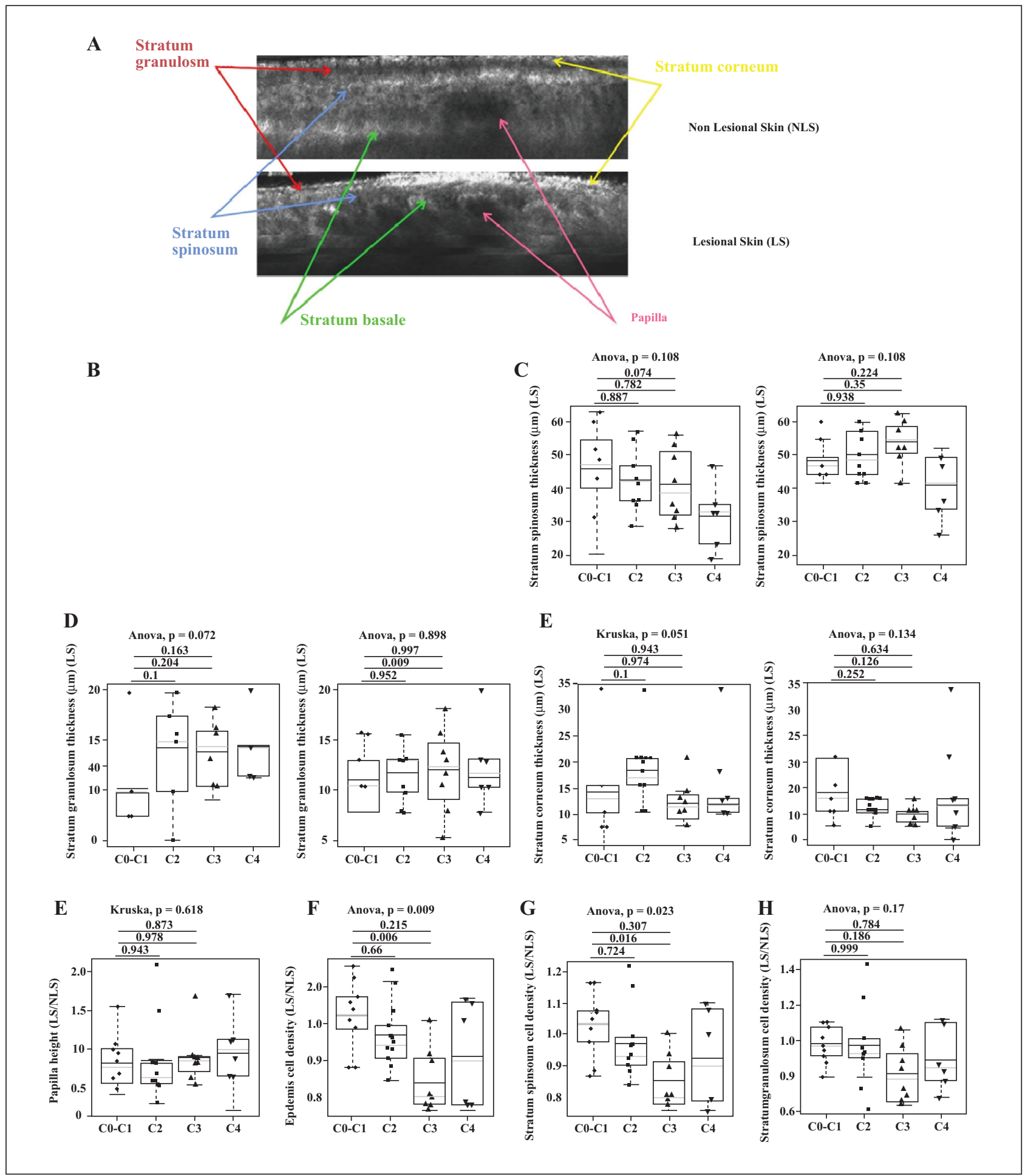

Figure 4. Epidermal structure analysis by confocal microscopy. A) Z-stack of confocal microscopy images of NLS (above) and LS (below). B-I) Black symbols represent individual data and horizontal black lines mean values. For each CEAP class, the grey boxplots represent the lower quartile, median (bold line) and upper quartile. Whiskers represent either the maximum value or 1.5 times the interquartile range, whichever is less. B-E) LS and NLS thickness measurement ( $\mu \mathrm{m})$ according to CEAP group in the epidermis $(\mathbf{B})$, stratum spinosum $(\mathbf{C})$, stratum granulosum $(\mathbf{D})$, and stratum corneum $(\mathbf{E})$. F) Measurement of the LS/NLS ratio of the height of papilla $(\mu \mathrm{m})$. G-I) LS/NLS ratio of cell density (cells $/ \mathrm{mm}^{2}$ ) for the epidermis $(\mathbf{G})$, stratum spinosum $(\mathbf{H})$, and stratum granulosum $(\mathbf{I})$. 


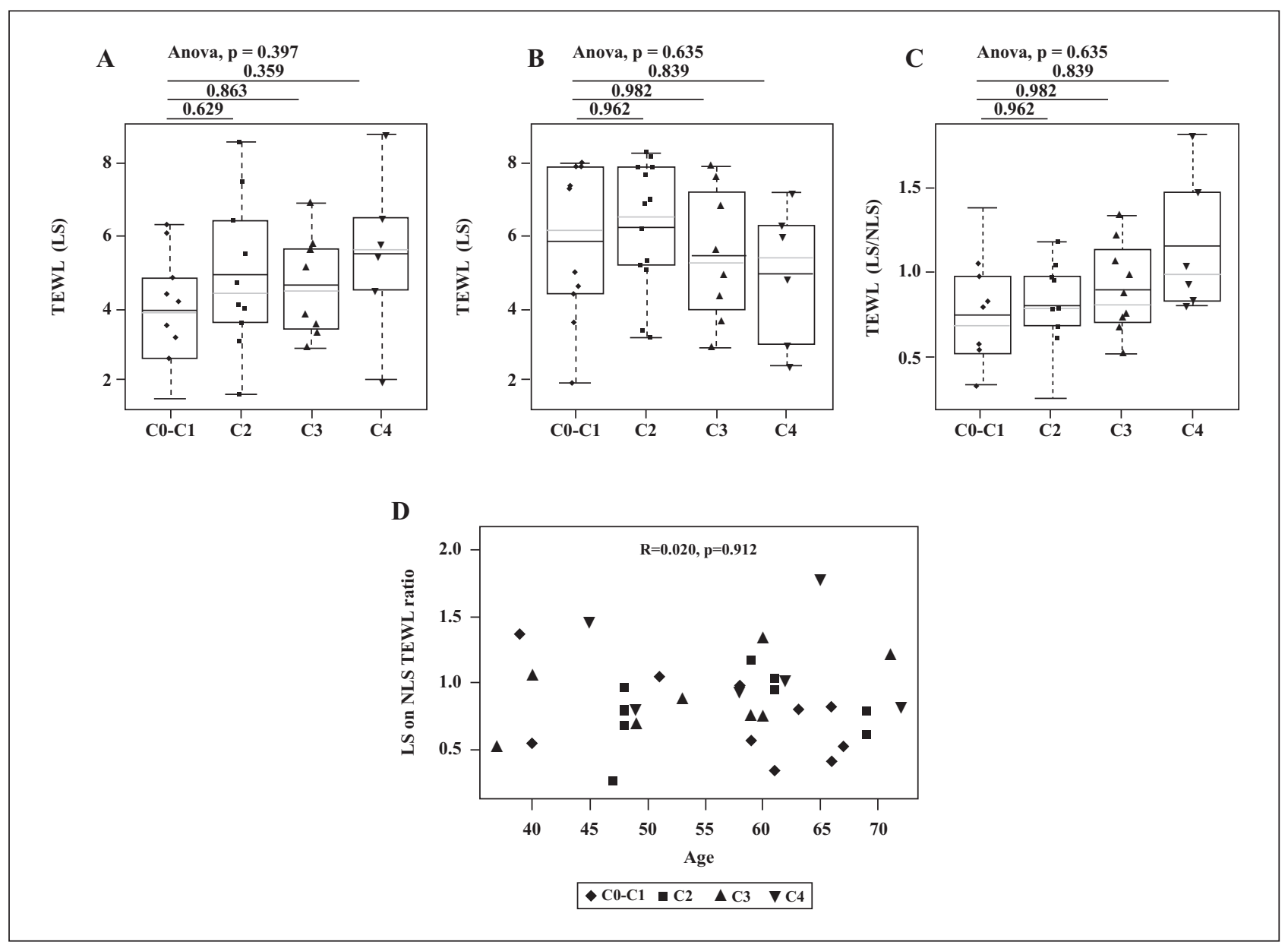

Figure 5. TEWL measurements $\left(\mathrm{g} / \mathrm{h} / \mathrm{m}^{2}\right)$ according to CVD severity (A-C) or age (D). A-C) Black symbols represent individual data and horizontal black lines mean values. For each CEAP class, the grey boxplots represent the lower quartile, median (bold line) and upper quartile. Whiskers represent either the maximum value or 1.5 times the interquartile range, whichever is less. A) TEWL according to CEAP groups for LS. B) TEWL according to CEAP groups for NLS. C) LS/NLS TEWL ratio according to CEAP groups. D) LS/NLS TEWL ratio according to the age of each CEAP group.

may be used for $\geq$ Stage C3. This will obviously require further prospective study.

Interestingly, the degree of skin barrier defect is the most important parameter related to eczema, as reported in atopic dermatitis or chronic hand eczema [23, 24]. As eczema is an integral part of CVD-related symptoms, one may wonder what the contribution of skin barrier alteration is in the development of eczema in CVD pathology. There are two main pathogenic hypotheses: the immune versus the barrier hypothesis. In the immune hypothesis, the vascular inflammation spreads into the skin, inducing the activation of keratinocyte innate immunity, leading to skin inflammation and eczema ("inside-out"). On the other hand, in the barrier hypothesis, skin barrier disruption allows transepidermal penetration of all molecules in contact with the skin surface, including allergens, irritants, pollutants, chemicals, microorganisms, etc., leading to the activation of skin immunity ("outside-in"). However, a combination of both phenomena cannot be excluded.

Over the last decade, the microbiota has emerged as a potential disruptive factor of skin barrier function and as an inducer of skin inflammation. Indeed, if there is a link between skin microbiota and atopic eczema, a direct role of the microbiota in the induction of eczema in moderate CVD has not been demonstrated [25]. In the most severe stages of CVD, Pseudomonas Aeruginosa may play a role in defective wound healing, protected by a shield mechanism (biofilm) against polynuclear neutrophils [26]. Moreover, bacteria are likely to promote delayed healing by inflammatory processes [27]. Numerous studies showed that the microbiota plays a key role in atopic dermatitis, specifically involving Staphylococcus Aureus, which is significantly more prevalent in the inflamed skin of patients [28, 29]. As the clinical features of atopic eczema (both inflamed and dry skin) are similar to those of CVD eczema, more precise investigations must be performed to understand the role of the skin microbiota in CVD.

Here, biometric methods have provided important insight into the structure and function of CVD skin in a noninvasive way. Alternatively, transcriptomic analysis may allow molecular features to be determined, however, this requires tissue sampling. Many studies have investigated gene expression in CVD, essentially related to vascular inflammation, but few have focused on the dermis and epidermis. Indeed, the evaluation of vessel inflammation is usually performed using vein samples collected during 
venous surgery procedures. The use of skin biopsies for transcriptomic analysis is avoided due to their invasive nature, largely due to the fear of wound healing complications in patients with CVD. However, altered expression in genes that encode for structural factors, mediators of inflammation, and apoptotic pathways in Stage C5 and C6 has been shown [30]. In addition, there are signs that keratinocytes at the non-healing edges of venous ulcers attempt to proliferate or differentiate, although this is not successful [31]. More recently, the use of minimally invasive skin tape strip RNA sequencing has led to the identification of different atopic dermatitis disease endotypes [32]. Such micro-invasive techniques may help in the future to identify skin molecular biomarkers related to CVD.

Regarding therapeutic options in CVD, flavonoids have been proposed [33], but currently clinicians suggest compression therapy, which has a positive effect on the symptoms of the pathology. Importantly, compression therapy significantly decreases TEWL [34], suggesting that its effect is both mechanical on the veins and antiinflammatory at the skin level. However, compression stockings are known to be uncomfortable as they lead to skin irritation and itching. A better understanding of the disease and its causes and consequences on the skin may help to find more appropriate, durable and comfortable treatments. In conclusion, we conducted an extensive characterization of skin modifications associated with mild-to-moderate stages of CVD and were able to detect skin changes paralleling CVD severity. We demonstrate that the use of non-invasive techniques can be used to adequately characterize CVD disease. These biometric methods could provide new insight for future therapeutic evaluation of CVD patients, especially in the field of medical devices.

Acknowledgments and disclosures. Acknowledgments: we thank Dermatec for expertise in skin procedures and study conduct, Jean-Christophe Pittet (ORION Concept) for his help on in vivo confocal microscopy and echographic analysis, Cécile Bultez (CPP Initiatives) for medical writing assistance, and the CIRI team for their scientific support. Financial Support: this work was supported by SIGVARIS SAS. Conflicts of interest: AP, AM, CB, KS, JFN, MV, TL and AN have no conflicts of interest to disclose. CC is employed by SIGVARIS SAS. AL (DERMATEC) received a grant for the study.

Open Access. This article is licensed under a Creative Commons Attribution 4.0 International License, which permits use, sharing, adaptation, distribution and reproduction in any medium or format, as long as you give appropriate credit to the original author(s) and the source, provide a link to the Creative Commons licence, and indicate if changes were made. The images or other third party material in this article are included in the article's Creative Commons licence, unless indicated otherwise in a credit line to the material. If material is not included in the article's Creative Commons licence and your intended use is not permitted by statutory regulation or exceeds the permitted use, you will need to obtain permission directly from the copyright holder. To view a copy of this licence, visit http://creativecommons.org/licenses/by/4.0/.

\section{References}

1. Beebe-Dimmer JL, Pfeifer JR, Engle JS, Schottenfeld D. The epidemiology of chronic venous insufficiency and varicose veins. Ann Epidemiol 2005; 15: 175-84.

2. Pannier F, Rabe E. Progression in venous pathology. Phlebology 2015; 30: 95-7.

3. Poredos P, Spirkoska A, Rucigai T, Fareed J, Jezovnik MK. Do blood constituents in varicose veins differ from the systemic blood constituents? Eur J Vasc Endovasc Surg 2015; 50: 250-6.

4. Caggiati $A$, Rosi $C$, Franceschini $M$, Innocenzi $D$. The nature of skin pigmentations in chronic venous insufficiency: a preliminary report. Eur $J$ Vasc Endovasc Surg 2008; 35: 111 1-8.

5. Lee AJ, Robertson LA, Boghossian SM, et al. Progression of varicose veins and chronic venous insufficiency in the general population in the Edinburgh Vein Study. J Vasc Surg Venous Lymphat Disord 2015;3: 18-26.

6. Pannier $F$, Rabe $E$. The relevance of the natural history of varicose veins and refunded care. Phlebology 2012; 27: 23-6.

7. Birdina J, Pilmane $M$, Ligers $A$. The morphofunctional changes in the wall of varicose veins. Ann Vasc Surg 2017;42: 274-84.

8. Ojdana D, Safiejko K, Lipska A, et al. The inflammatory reaction during chronic venous disease of lower limbs. Folia Histochem Cytobiol 2009; 47: 185-9.

9. Metcalfe $M$, Baker DM, Burnstock G. Purinoceptor expression on keratinocytes reflects their function on the epidermis during chronic venous insufficiency. Arch Dermatol Res 2006; 298: 301-7.

10. Sansilvestri-Morel $P$, Fioretti F, Rupin $A$, et al. Comparison of extracellular matrix in skin and saphenous veins from patients with varicose veins: does the skin reflect venous matrix changes? Clin Sci (Lond) 2007; 112: 229-39.

11. Angelova-Fischer I, Wuthe D, Zillikens D, Kahle B. Noninvasive bioengineering assessment of the skin barrier function in patients with chronic venous insufficiency. Br J Dermatol 2010; 162: 1071-5.

12. Peschen $M$, Grenz $H$, Lahayé $T$, et al. Changes of cytokeratin expression in the epidermis with chronic venous insufficiency. Vasa 1997; 26: 76-80.

13. Wade R, Paton F, Woolacott N. Systematic review of patient preference and adherence to the correct use of graduated compression stockings to prevent deep vein thrombosis in surgical patients. J Adv Nurs 2017; 73: 336-48.

14. Launois $R$, Mansilha $A$, Lozano $F$. Linguistic validation of the 20 item-chronic venous disease quality-of-life questionnaire (CIVIQ-20). Phlebology 2014; 29: 484-7.

15. Gonzalez S, González E, White WM, Rajadhyaksha M, Anderson RR. Allergic contact dermatitis: correlation of in vivo confocal imaging to routine histology. J Am Acad Dermatol 1999; 40: 708-13.

16. Longo C, Zalaudek I, Argenziano G, Pellacani G. New directions in dermatopathology: in vivo confocal microscopy in clinical practice. Dermatol Clin 2012; 30: 799-814.

17. Alexander $\mathrm{H}$, Miller DL. Determining skin thickness with pulsed ultrasound. J Invest Dermatol 1979; 72: 17-9.

18. Caggiati A. Ultrasonography of skin changes in legs with chronic venous disease. Eur J Vasc Endovasc Surg 2016;52: 534-42.

19. Barel $A O$, Clarys $P$, Lambrecht $R$. In vivo study of the mechanical properties of the human skin with the suction method (Cutometer). The 10th International Symposium of Bioengineering \& the Skin, Cincinnati. June 13-15, 1994.

20. Dobrev $\mathrm{H}$. Value of the noninvasive skin bioengineering methods in patients with scleroderma. Rheumatology (Bulgaria) 1998; 2: 15-7. 
21. Barel AO, Clarys P. Study of the stratum corneum barrier function by transepidermal water loss measurements: comparison between two commercial instruments: Evaporimeter and Tewameter. Skin Pharmacol 1995; 8: 186-95.

22. Distante F, Berardesca E. Transepidermal water Loss, bioengineering of the skin: methods and instrumentation. CRC Press, 1995.

23. Kelleher $M$, Dunn-Galvin $A$, Hourihane JOB, et al. Skin barrier dysfunction measured by transepidermal water loss at 2 days and 2 months predates and predicts atopic dermatitis at 1 year. J Allergy Clin Immunol 2015; 135: 930-5 el.

24. Tauber $M$, Bérard $E$, Lourari $S$. Latent class analysis categorizes chronic hand eczema patients according to skin barrier impairment. J Eur Acad Dermatol Venereol 2020; 34: 1529-35.

25. Marrs $\mathrm{T}$, Flohr $\mathrm{C}$. The role of skin and gut microbiota in the development of atopic eczema. $\mathrm{Br} J$ Dermatol 2016; 175: 13-8.

26. Bjarnsholt $T$, Kirketerp-Møller $K$, Jensen $P \varnothing K$, et al. Why chronic wounds will not heal: a novel hypothesis. Wound Repair Regen 2008; 16: 2-10

27. Fazli $M$, Bjarnsholt T, Kirketerp-Møller K, et al. Nonrandom distribution of Pseudomonas aeruginosa and Staphylococcus aureus in chronic wounds. J Clin Microbiol 2009; 47: 4084-9.
28. Kim J, Kim BE, Ahn K, Leung DYM. Interactions between atopic dermatitis and Staphylococcus aureus infection: clinical implications. Allergy Asthma Immunol Res 2019; 11:593-603.

29. Tauber $M$, Balica $S$, Hsu C-Y, et al. Staphylococcus aureus density on lesional and nonlesional skin is strongly associated with disease severity in atopic dermatitis. J Allergy Clin Immunol 2016; 137: 1272-4 e3.

30. Charles CA, Tomic-Canic M, Vincek V, et al. A gene signature of nonhealing venous ulcers: potential diagnostic markers. J Am Acad Dermatol 2008; 59: 758-71.

31. Stojadinovic O, Pastar I, Vukelic S, et al. Deregulation of keratinocyte differentiation and activation: a hallmark of venous ulcers. J Cell Mol Med 2008; 12: 2675-90.

32. Dyjack N, Goleva E, Rios C, et al. Minimally invasive skin tape strip RNA sequencing identifies novel characteristics of the type 2-high atopic dermatitis disease endotype. J Allergy Clin Immunol 2018; 141: 1298-309.

33. Rabe E, Guex JJ, Morrison N, et al. Treatment of chronic venous disease with flavonoids: recommendations for treatment and further studies. Phlebology 2013; 28: 308-19.

34. Takai $Y$, Hiramoto K, Nishimura Y, Ooi K. Relationship between biochemical factors and skin symptoms in chronic venous disease. Arch Dermatol Res 2017;309: 253-8. 